although a fair working knowledge of biochemistry, and in a series of twelve contributed chapters critically summarizes the state of knowledge in a number of areas.

After two brief introductory chapters on the chemical composition of animal viruses (M. Green) and on virus architecture as determined by X-ray diffraction and elcctron microscopy (C. F. T. Mattern), there follow a series of reviow chapters each dealing with a major group of viruses. Baltimore's review of the replication of the picornaviruses is outstanding: detailed, critical and with many stimulating suggestions for the future. Probably more is known about this group of small RNA viruses than about any other group of animal viruses, and yet a brief list of the major unsolved problems occupies two pages.

The genetic analysis of one of the picornaviruses, poliovirus, has been taken further than that of any other virus and is the subject of an excellent review by Cooper, who has himself pioneered this field. Two shorter reviews of two major groups of RNA viruses follow: the myxoviruses reviewed by C. Scholtissek, R. Drzeniek and R. Rott, and the reoviruses reviewed by C. J. Gauntt and A. F. Graham. These three groups represent the three ways in which an RNA genome exists-as a single-stranded RNA in the picornaviruses, synthesizing a single protein which is later specifically broken down to produce both the virion and non-virion proteins; as multiple pieces of single-stranded RNA in the myxoviruses, oach probably coding for an individual protein, and as multiple pieces of double-stranded RNA in the reoviruses. J. P. Bader then reviews the complex subject of the RNA tumour viruses, skilfully guiding the reader through this complex and fascinating subject. There follow four chapters on the biochemistry of adenovirus infection (H. S. Ginsberg), of poxvirus replication (B. R. McAuslan), of herpesvirus multiplication (B. Roizman) and finally of DNA-containing bacteriophages (C. K. Mathews). Each of these is critical, comprehensive and to be highly recommended. Finally, a chapter on interferon (H. B. Levy, S. Baron and C. Buckler) provides a concise summary of prosent knowledge of this viral inhibitor, which is being used both as a tool in the analysis of virus multiplication and as a way of investigating genetic control in eucaryotic cells.

I have a few adverse comments-it is a pity that a chapter on DNA tumour viruses had to be cancelled at the last minute, a chapter on the arboviruses and on RNA bacteriophages would have been worthwhile, and one or two of the chapters are insufficiently critical to be of the greatest value. It is expensive too-but I thought worth it.

D. C. BURKE

\section{TRIBUTE TO DE BOER}

\section{Physical and Chemical Aspects of Adsorbents and} Catalysts

Edited by B. G. Linsen. Pp. xxiv + 650. (Academic Press: London and New York, January 1970.) 150s; $\$ 23.50$.

THIs book is a festschrift written by a group of Dutch scientists who "during their study and work have profited by the expert guidance and stimulating influence of Professor J. H. de Boer". 'The occasion is do Boer's retirement from the Technological University of Delft. The overall theme of the book is the research initiated and stimulated by de Boer, more particularly his contributions to the study of adsorption and catalysis. The kinetic view of the adsorption process and the deduction of the thermodynamic consequences of various possible modes of adsorption on a surface form an important part of de Boer's scientific thinking. Naturally therefore this approach illumines several of these articles contributed by de Boer's pupils.

In the first two chapters we are given authoritative reviews on the characteristic features of adsorption by substrates which either contain pores or are essentially homogeneous. The difficulties which attend the thermodynamic description of two-dimensional phase-transitions of gas adsorbed on a surface are particularly well dealt with. The requirement that the adsorption sites be strongly polarizing in character in order to allow the otherwise infrared-inactive vibrational mode of nitrogen to be observed is tied in elegantly with the experimentally observed entropy of adsorption of nitrogen on nickel in a chapter on recent calculations of the entropies of adsorbed molecules. Comprehensive but specialized surveys of the properties of the group of important oxide catalysts alumina, silica, magnesia and zirconia will interest all whose work lies in this area, while two chapters which reflect de Boer's connexion with the nuclear energy programme discuss the hydroxide-precipitation of uranyl salt solutions and the surface texture of various forms of carbon. Nickel supported on silica has for long been an important industrial catalyst, and the relationship of the structure of the catalyst to its catalytic activity for two hydrogenation reactions is discussed in detail.

The final article, which is also tho longest, has a rather different approach, in that it deals with the phenomena of chemisorption from an essentially atomic viewpoint. It provides an exhaustive survey of the reactions of oxygen with tungsten and molybdenum, reactions on which the full panoply of modern experimental techniques has been brought to bear. The results of measurements of heats of adsorption, work-function changes, resistance changes, low energy electron diffraction patterns together with mass-spectrometric analysis of the species desorbed by heating or by electron impact are described, discussed and interrelated.

It seems likely that all those working in the fields of chemisorption and catalysis will find something to interest them in this book, though perhaps few will find all tho articles equally interesting. This is a well produced and well written book in which it is very seldom indeed that one is aware that the authors are not writing in their native language; but the description of one of de Boer's theories as "astonishingly ambiguous" (= astonishingly ingenious ?) is a delightful malapropism.

R. P. H. GASSER

\section{METAL COMPLEXES IN SOLUTION}

Ion Exchange and Solvent Extraction of Metal Complexes By Y. Marcus and A. S. Kertes. Pp. ix +1037. (Wiley (Interscience): London and New York, May 1969.) $315 s$.

THE unequal distribution of a species between two dis. crete phases has long formed the basis of innumerable separation procedures of outstanding importance in analytical chemistry and industrial practice. The same techniques have been applied extensively in studies of the nature and composition of metal complexes in solution.

Although there are a number of well known books dealing severally with liquid-liquid extraction and the use of ion-exchanges, this volume is the first to attempt a really comprehensive yet detailed account of the funda mental physical chemistry involved.

The book starts with a review of current views on electrolytes in homogeneous solutions and continues with accounts of organic solvents and non-aqueous solutions and mixtures which many readers will find particularly useful. The formation in solution of ion-pairs and complexes precedes a thorough account of ion-exchangers, their structure and properties, selectivity, sorption and swelling phenomena and their behaviours in coneentrated solutions and mixed solvents. This handles a mass of complicated theory in as clear a manner as the material permits. 